the Medical Council held should be accepted merely for the former department. The Edinburgh College of Surgeons had also long given a general qualification for practice, in their diploma, and indeed justly boasted of having taken a lead in extending the scope of medical study; but, on the principle of requiring a double qualification, were restricted to surgery.

There was thus a field opened up for the Edinburgh College of Physicians, who had previously not taken any part in medical education, but then resolved to give licences not only for supplementing the surgical diploma, but for comforting the English apothecaries, who languished under the ignoble title of general practitioners. These gentlemen they took under their wing, and, without any examination, hatched them as full-fledged physicians, at the moderate charge of ten guineas a piece, so as within a year to replenish their coffers to the amount of no less than $£ 10,000$, anci have since driven a thriving trade in the less objectionable form of requiring an examination of their candidates.

The double qualification being thus established, the Universities of Scotland, in self-defence and with great reluctance established a Mastership of Surgery, which was given without any addition to the study or examination required for the degree of M.B.

All this having been so arranged, it was pointed out to the Council, that the object mentioned in the preamble of their Act would be imperfectly accomplished, since men might be registered as Surgeons or Physicians, with a qualification limited to one of these departments, so that a patient who had broken his leg, might send for a doctor who could only prescribe physic, while another might seek aid for a sore-throat from one who had no authority to give him a dose of medicine. It was then resolved that no person should be registered who had not gone through the whole course of medical as well as surgical study; and so the case stands at present, the double qualification being still deemed necessary, although it requires the same education from two different bodies, than which it is not easy to imagine anything more absurd or injurious. The bad effects thus resulting, and the means of remedy that may be employed, will, with your permission, be discussed in another letter. I am, Sir, yours truly,

Edinburgh, 2nd Jan., 1870.

JAMES SYME.

\section{ALCOHOLIC STIMULATION IN DISEASE.}

\section{To the Editor of THe LANCET.}

SiR,-The admirable leader in your last number leaves little to be said upon the discreet use of alcohol, except on the point which has more especially led me to rank with those who are extremely cautious in recommending stimulants to their patients. I do not object to the medical man employing alcohol if his judgment approve of its use, for he has as much right to administer it as any other form of medicine or diet; but I do strongly object, in the present unsettled state of the question as to the value of alcohol as food, to his assuming that he possesses in it an equivalent for good nourishment. This assumption and grievous practical error I am witnessing every day. The instance, perhaps, where the error is most striking is in a case like that of enteric fever, where good feeding is so necessary, and where we have an opportunity of comparing the results of private and hospital practice. Now, in a disease of this kind, in which the temperature is six degrees above the normal standard, indicating an excessive amount of tissuechange in the body, and which, according to physiologists, is equivalent durin one day to what wovld take place if the patient, in health, had walked fifty miles, it is evident that much nutriment is required. Theoretically, this is obvious; and, practically, the profession has universally acreed to follow Graves's dictum-to "feed fevers." Now, since the condition of the alimentary canal precludes the use of solid food, it might be thought that milk was the best substitute; and, as a matter of fact, I may say for myself that since I have treated my patients on four or fire pints of milk daily my success with ferer has been much greater than heretofore.

Now what do I constantly witness in private practice? The patient I risit is a young lad or roung lady, and the doctor and myself perfectly agree as to the nature of the case, the course it will run, and the treatment required; further, to ensure the fulfilment of his orders, the services of two nurses have been procured, one of whom is in constant attendance with a devoted mother and sister. Now what is the condition of the patient who has been ill a fortnight with enteric fever? He is extremely wasted, his skin dry and hot, restless, wakeful or delirious, tongue parched, and his pulse 150. I am informed that the patient has had plenty of nourishment, and am shown the table before me covered with curs of beef-tea, jelly, brandy bottles, physic bottles, and wine decanters. I am further assured that the patient has had three or four cups of beef-tea daily, some jelly, eight or ten ounces of brandy, five or six glasses of champagne, and his medicine containing five grains of ammonia every four hours. To prove the regularity of the administration of these different things, the nurses display their written papers as vouchers. It is now evident that the patient is dying of starvation and stimulation. No mortal man could be in any other condition who had been attempting to live on a little beef-tea and jelly for a fortnight, supplemented by brandy, champagne, and ammonia. In fact, I scarcely know a better formula to produce wasting, hot skin, parched tongue, irritable heart, restlessness and delirium. I am not overdrawing the picture, and as for modifications of it, I witness them every day. I have no objection to wine or brandy in their proper place, and when judiciously administered ; but I do strongly object to the assumption that they can be for any lengthened period of time taken as substitutes for food. $I$ confess, too, to be almost overcome with regret when I see my hospital patients doing well, and see the young people in a rich man's house literally dying of starvation and stimulation.

I am, Sir, your obedient servant,
Grosvenor-street, W., Jan. 3, 1870.
SAMUEL WiLKS.

** We agree most heartily with Dr. Wilks as to the first-rate importance of administering plenty of milk to febrile patients; and no doubt the practitioner who neglects to use this form of nutriment, when the stomach will bear it (as it usually will), commits a serious error. But we must say that it certainly is not at all in accordance with our observation that alcohol quickens the pulse in fever, unless it be given in quite unsuitable cases, or in the clumsy and unscientific method of large single doses, instead of numerous small ones. On the contrary, nothing is more remarkable than the effect of alcohol, properly given, in slowing the pulse, while at the same time its tension is raised. The "wasting, hot skin, parched tongue, irritable heart, restlessness, and delirium," which Dr. Wilks speaks of, ought fairly, we think, to be ascribed to the foolish attempt to feed pyrexial patients without milk, rather than to alcohol, even supposing that to have been injudiciously used. And as regards the " unsettled state of the question as to the value of alcohol as food," we cannot quite allow that to pass unchallenged. Alcohol, as such, has been most abundantly proved to disappear, in great part, within the organism; and this oxidising process must evolve force. That the force so evolved does assist vital function is scarcely now to be doubted. The reason why alcohol is not universally useful in fever seems to be owing to the differences in the rapidity with which different patients carry on this secondary digestive process within the blood. Where it is slowly and with difficulty performed, narcotic depression of the nervous system more than counterbalances for evil the nutritive advantages of the alcohol.-ED. L.

\section{AN APPEAL TO THE PROFESSION.}

To the Editor of THE LAxCET.

SIR, - The Committee of the Medical Benerolent Fund earnestly crave your assistance in bringing before the profession the great need of a number of applicants - medical men, their widows and orphans, whom they are powerless to aid at present from want of funds.

During the past year the calls upon the IIedical Benero- 
lent Fund have been more numerous than at any time since the commencement of the Fund in 1836 . The number of cases relieved in 1869 (besides the 35 annuitants) is 125 , as against 106, the highest number in any previous year. In this way upwards of $£ 1000$ hare been expended, in grants varying in amount from 22 to $\& 20$.

At ourmeeting on Tuesday last there were 19 applications, but unfortunately we had less than $\$ 50$ at our disposal, and as a consequence most of these have been postponed for a month, in the hope that by that time means will be forthcoming to relieve them. Some of these cases are indeed of a most painful character. Five are widows, whose husbands have recently died while still in their prime, each leaving a large family, and in only one of these is there any sort of provision, and this only a policy of insurance for $\$ 500$, for a widow and ten children. Another is a widow who has for several years striven hard, with varying success, to support herself and children, but who is now obliged to succumb from failing sight and inability to obtain employment. Two others are ladies-orphans- who have for some years maintained themselves, and aided their respective families, as governesses; but phthisis in one case, and a very painful malady in the other, have obliged them to give up their ituations, and to seek assistance from this society. And such are but average specimens of the cases brought before sur Committee for investigation month alter month, and to assist in relieving those we appeal with confidence to our brethren, some of whom have indee given most liberally, both in time and money; but still there are doubtless thousands more who have the means and the heart, but who know nothing of this quietly-working Benevolent Fund, and it is to these more especially that we look for help on this New Year's Day.

The benevolence of the Medical Profession, is universally admitted and admired; surely it will not be lacking towards those of its own body in distress, nor will its charity be denied to the widows and orphans of its own members.

Contributions will be thankinlly received by either of the undersigned, and acknowledged in THE LANCEr.

Chaples J. FAfe, M.D., Treasurer, 57, Brook-stret, Grosvenor-square

STAMFORD FELCE, L.P.C.P., 12, Chipperhemi-road, St. Peier's-park, w. Hon. R. Thorne Thorne, M.B. 12, Seymour-street, Portman-sunarc, w.

Jan. 1st, 18:0. Secs.

\section{PUNCTURED WOUND OF THE THORAX TRANS- FIXING THE LEFT VENTRICLE.}

\section{To the Editor of THe LANCET.}

Sir,-The "Outrage at Ewell," by wilfully blowing up a house with gunpowder, will be fresh in the memory of your readers from the accounts in the daily press.

Some account of the condition of the man Huggett, who committed the atrocious act, and was found with a wound of the throat and a stab over the region of the heart, may $b \in$ of professional interest, more especially as a medico-legal question arose with regard to the power of the man to selfinflict the wounds so shortly after exposure to the shock of an explosion of $28 \mathrm{lbs}$. of gunpowder.

I was called to the scene of the explosion on the morning of the $22 n d$ Dec., and reached the spot about half an hour after the occurrence. I found the man Huggett lying on his back amongst the fallen bricks and détis in the front room of the adjoining house to that in which the explosion had taken place. He had been driven through with the forcing in of the partition wall. The explosion had reft the walls of the house in all directions, and blown a stack of chimneys from their base on to the roof. Huggett was insensible at the time I arrived, breaching slowly and feebly, with a futtering pulse, and cold surface. I poured some brandy between the teeth, which gradually passed down the throat, and repeating this once or trice consciousness slowly returned. He sinelt strongly of exploded gunpowder; his hands wele burnt, and his face blackened and charred. His clothes were burnt in rarious places, but there was no serious burn of the body. An open clasp knife was picked ap by his side. On the throat was a sapericial wound about two and a half inches long, dividing the shin and superficial fascia only, and jagged as though inflicted with a blunt instrument. Blood was not flowing from this wound. On raising the guernsey and flannel shirt from the abdomen and thorax they were found saturated with blood, which was now seen to flow from a punctured wound of the thorax. This wound kas transverse, measuring half an inch. It was on the lower edge of the fifth rib, in a line with the nipple, and three-quarters of an inch belowit. No ribs were fractured, but on firm pressure over them air passed out of the wound. The little finger just entered the wound, and could be passed between the fifth and sixth ribs through the divided intercostal muscles.

His state two hours afterwards was as follows:-Consciousness perfect; answered questions, and gave his reason - jealousy - for committing the act. He was very restless, raising himself on his elbow continually, and begging for cold water. Pulse 86, moderately full and regular; surface warm except the feet; shivers when the surface of the trunk is exposed; breathing hurried; general distress great, which I understand continued to increase up to the time of his death, six hours after the injury. I regret that my duties to the two other injured men and a call to a confinement rendered me unable to see Huggett again during life.

Sectio Cadaveris.-On enlarging the external wound 'on the thorax, the surface of the heart came into view. The pericardium contained a coagulum weighing $6 \mathrm{oz}$. On the surface of the left ventricle, an inch and a quarter from the apex of the heart, and corresponding with the parietal wound, was a transverse wound measuring five-eighths of an inch, the exact counterpart in shape of the blade of the knife already mentioned. On raising the heart this wound was seen to pass completely through its substance, puncturing the pericardium behind it, and slightly entering the lung, which had collapsed. When the ventricle was opened the puncture was seen to have traversed its cavity, close to the apex, dividing some of the columnæ carneæ. The left pleura contained nearly a pint of bloody fluid.

The organs of the body generally were healthy. A question was raised by some of the jury whether the wounds were self-inflicted. It was known that a scuffle had followed Huggett's entrance of the house between him and Spooner (now dead), the occupant. Huggett was insensible when found some minutes after the explosion. He remained so when I reached him. Spooner, who was pushing him out of the honse, said he saw no knife in Nuggett's hand. While in the act of pushing him, Huggett threw something towards the fire, and the explosion took place. The knife is shown to have belonged to Huggett. Spooner and the third man injured were sensible immediately after the explosion; one of thein, in fact, ran into the street on fire.

There seems no reason, therefore, why Huggett may not have been conscions, and, having committed a dreadful crime, have come to the desperate determination of destroying himself as he lay in the ruins he had made. I am, Sir, your obedient servant,

Dorset House, Ewell, Jan. 1870.

G. R. BARNES, M.D.

\section{DIMINUTION OF CONTAGIOUS DISEASES AT WINDSOR.}

To the Editor of The Lancet.

SIR,-As much has been said for and against the advis ability of extending the Contagious Diseases Act to the civil population, I send you a few facts which may prove not only ixteresting, but instructive, as to its efficient working in one of our garrison towns.

The battalion to which $\mathrm{I}$ belong left London for Windsor on the Ist of March, 1869, and as the Contagious Diseases Act was in force in that town, the men were carefully examined immediately after their arrival, and those found affected were sent to hospital for treatment. The admissions for venereal during the first four months of our stay were only thirty; nearly all the cases were of a mild form, and readily amenable to simple treatment. Upon the 1st of September the battalion returned to town, and was quartered at Chelsea barracks; the number under treatment was then only seven. From that date to the present, venereal disease has been greatly on the increase; as many as 108 cases 